\title{
The evidence for urodynamic investigation of patients with symptoms of urinary incontinence
}

\author{
Peter F Rosier
}

Address: University Medical Centre Utrecht, Department of Urology, C 04.236, P.O. Box 85500, 3580GA Utrecht, The Netherlands

Email: p.f.w.m.rosier@umcutrecht.nl

FI000Prime Reports 2013, 5:8 (doi:10.12703/P5-8)

This is an open-access article distributed under the terms of the Creative Commons Attribution-Non Commercial License (http://creativecommons.org/licenses/by-nc/3.0/legalcode), which permits unrestricted use, distribution, and reproduction in any medium, provided the original work is properly cited. You may not use this work for commercial purposes.

The electronic version of this article is the complete one and can be found at: http://fl $000 . c o m / p r i m e / r e p o r t s / m / 5 / 8$

\begin{abstract}
Urodynamic studies are the gold standard to objectively diagnose dysfunction of the lower urinary tract. The widely available evidence for the clinical relevance is, however, fragmented. This article summarizes the published knowledge supporting the use of urodynamic studies in urinary incontinence in female, male and frail patients, as well as patients with relevant neurological disease. Five technological innovations are discussed briefly. Standard urodynamic cystometry can, on the basis of a solid body of evidence, objectively unveil the entire function of the lower urinary tract in all patients with urinary incontinence, regardless of the patients' perception of (ab-)normality of signs and or symptoms.
\end{abstract}

\section{Introduction}

Lower urinary tract function and dysfunction can be measured objectively with urodynamic investigation. Urodynamic investigation requires a catheter to be inserted in the urinary bladder to measure intravesical pressure (i.e. in the urinary bladder) and a catheter in the rectum or vagina that measures the intra-abdominal pressure surrounding the bladder. Bladder muscle function can be deduced from the pressure difference between intravesical and intra-abdominal pressures. While the bladder fills, via a filling lumen in the transurethral or suprapubical intravesical catheter, the adaptation of the bladder muscle to the volume increment can be observed. Likewise, during emptying (alongside the pressure-recording catheter) the intravesical pressure can be measured together with the expelled fluid flow. This flow can be measured in a beaker that records the volume increment, and integrated to deduce the flowrate in $\mathrm{mL} / \mathrm{s}$. Urodynamic investigation and the terms used in functional (neuro-) urology and urodynamics are standardized $[1,2]$. As well as abnormalities of emptying, storage function can also be observed.

Urinary incontinence is a prevalent storage dysfunction. Urodynamic investigation is applied to differentiate stress urinary incontinence from urgency urinary incontinence. The urethral closure function is insufficient in stress urinary incontinence and the volume adaptation is insufficient in urgency urinary incontinence. Usually, the detrusor contracts too early in urgency urinary incontinence, and this is termed detrusor overactivity. Detrusor overactivity may cause frequent and urgent voiding (with or without urinary incontinence); a combination of symptoms that is usually referred to as overactive bladder syndrome - a syndrome that is, however, neither specific nor sensitve to the urodynamic diagnosis of detrusor overactivity.

\section{Urodynamic studies}

As with many diagnostic tests in medicine, the technique used for urodynamic investigation has developed over the years and has gradually been implemented in clinical practice from its first clinical applications in the late 1950s until now. Technical developments, as well as increasing knowledge about lower urinary tract neurology, physiology and pathophysiology have refined our insight into the diagnostic possibilities of urodynamic investigation. The invasiveness of urodynamic investigation remains a drawback and raises the threshold for its use, although the true morbidity is modest. Alternatives 
have been sought in precise and/or standardized clinical evaluation and grading of the patients' perceived symptoms, but have consistently failed to achieve a predictive value that is reliable in clinical practice $[3,4]$. More recently, alternative methods to evaluate the function of the lower urinary tract have been developed, most of them with the aim of avoiding the need for transurethral catheterization $[5,6]$.

The general consensus is that the "definitive level 1 study" to show the clinical value of urodynamic investigation for urinary incontinence has never been published, and that the overall level of evidence for the clinical value of urodynamic investigation is low [7]. There is, however, a large body of evidence for urodynamic investigation of patients with urinary incontinence, but this evidence is rather scattered throughout the literature. This work intends to give an overview of the current state of the art of urodynamic investigation for patients with urinary incontinence.

\section{Normal values, reliability and diagnostic performance}

There is a great variety of literature about inter-observer variation, test-retest, and practice variation and short-term (i.e. within the session), intermediate-, and long-term reproducibility of urodynamic investigation. A number of reports describe what can be summarized as a test-retest variation of $\pm 10-15 \%$ for various parameters (volume, pressure or flow). Basically, this variation can be regarded as the physiological variation of lower urinary tract function [8]. Diverse studies have, however, also demonstrated clinically relevant inter-practice variation, and inter-rater/observer variation, so applying standard techniques and continuous quality control is of the utmost importance $[9,10]$.

There have also been studies that provided values for volume, compliance and filling sensation(s) during cystometry that can be regarded to be "normal" [11-13]. These studies have been helpful in understanding lower urinary tract function, but there is also some evidence that the evaluation of filling sensation and of "capacity" may be different between laboratories, and thus "may be observer-dependent". This makes data exchange, as well as generalization and interpretation of published data, difficult. It is important, while judging the result of urodynamic investigation, to bear in mind neuroanatomy and -physiology, including test-retest variation and the sensations that can be expected in healthy persons [9]. Also, the laboratory situation may cause a variation in the patient's usual "lower urinary tract behaviour". This means that volumes and urodynamic filling sensations and capacity have to be weighed against the information from the patients' voiding diary [14].

Urodynamic testing for (bladder storage phase) urinary incontinence is incomplete without evaluation of the voiding phase. Flow rate during voiding may also be less with a catheter in the urethra and, to some degree, this can be caused by the size of the catheter [1]. Such "mechanical" effects are, however, usually larger in male than in female patients [15]. Possibly, the test situation being stressful for the patient - together with the catheter, influence the voiding. Dual catheter cystometry methods seem disadvantageous in this regard, because removal of a separate filling catheter just before (attempted) micturition interferes with lower urinary tract function and may also displace the intravesical pressure-sensing catheter $[1,16]$. As thin as possible (e.g. 5-7F), double-lumen catheters for filling and pressure recording during urodynamic investigation are regarded as the gold standard [1], and the majority of patients are able to void relatively well with these in place. Nevertheless, investigators should interpret pressure-flow voiding parameters and the subsequent post-void residual urine together with the catheter-free voiding parameters, preferably of multiple flows.

\section{Urodynamic testing}

\section{Female patients with signs of urinary incontinence}

The majority of studies to date demonstrate a weak correlation between symptoms and the results of urodynamic investigation, especially cystometry, in patients with urinary incontinence $[3,4,17,18]$. This indicates that symptom assessment does not give very sensitive, nor very specific, results with which to define the precise dysfunction of the lower urinary tract. Recruitment of data from a recent large study demonstrates that only a very small proportion of patients referred with urinary incontinence could be diagnosed as "uncomplicated stress-predominant urinary incontinence" on the basis of symptoms and the sign of urinary loss during stress testing $[19,20]$. Nevertheless, the correlation of the symptom "stress urinary incontinence" (expressed by the patient or concluded after questioning by the physician) with the result of urodynamic investigation is somewhat better than the correlation of urgency urinary incontinence (expressed, or questioned) with urodynamic investigation [21]. When frequent voiding, urgency and/or urgency urinary incontinence is part of the symptom complex of patients with urinary incontinence, urodynamic investigation is of value to obtain an objective diagnosis [12-24]. Objective diagnosis is warranted when signs and symptoms do not exclusively direct one to stress urinary incontinence. 
Patients with initial presentation of urinary incontinence, which is a sometimes devastating but usually not life-threatening dysfunction, can, however, be treated conservatively on the basis of specific clinical examination and a drinking-voiding diary, preferably over three days and determination of post void residual urine, preferably after flowmetry [25]. In cases of all types of urinary incontinence, where conservative measures have not been successful, and particularly if relevant (neurological) co-morbidity exists on relevant previous surgery that has been performed, urodynamic investigation is usually necessary before initiating a specific and/or more invasive treatment [26].

The results of urodynamic investigation must always be compared with the patients' signs and symptoms, and interpreted in the context of the expressed symptoms, voiding diary and clinical (or other) examinations in order to obtain a sound diagnosis.

There have not been any studies to show differences in patterns of neurogenic or idiopathic detrusor overactivity. Existing studies have been unable to reliably quantify the severity of detrusor overactivity, in a clinically or scientifically useful way $[23,24]$. No evidence that the cause, neurogenic or idiopathic, or the severity as perceived by the patient, of detrusor overactivity can be diagnosed from urodynamic investigation (cystometry). A recent review [29] concluded that the incidence of detrusor overactivity is higher when the patient is in the sitting position during cystometry, rather than the supine position [27], and furthermore, there is some evidence that moving to a toilet, the sound of water and hand washing can cause detrusor overactivity.

No publications have shed light on the sensitivity and specificity of imaging and electromyograph adjunct to cystometry, nor are there studies that allow extrapolation to the added value of ambulatory urodynamics [26].

Various publications have shown that values of urethral pressure (profile) parameters in women with, or without, incontinence are largely overlapping and that urethral pressure(s) is affected by the volume of fluid in the bladder, the position of the patient and the orientation of the pressure sensor within the urethra [28]. The poor sensitivity and specificity of urethral pressure measurements and their large test-retest variation limits their value in patients with urinary incontinence. Furthermore, reliable "sub-typing" of urinary incontinence between stress urinary incontinence and detrusor overactivity on the basis of urethral pressures has never been possible. Various studies have shown conflicting results of urethral function tests, such as urethral profiles and closure pressures or leak point pressures in relation to urinary incontinence severity $[17,18,29,30]$. Contemporary urethral function tests are only very modestly suited to further "sub-categorize" patients with stress (predominant) urinary incontinence for treatment, or to judge the severity of incontinence [34]. If performed, urethral pressure measurements should be judged while taking other urodynamic investigation (such as cystometry) and clinical examination into account. Parameters from abdominal leak point pressures measurements are not reliably helpful as single predictors of success for suburethral sling or tape treatment of patients with stress urinary incontinence [30,31]. Abdominal leak point pressures measurement cannot be used as a single urodynamic investigation to predict treatment success for patients with urinary incontinence.

Several studies have shown that the results of urodynamic investigation alone do not perfectly predict the treatment response in all patients: neither in patients with urinary incontinence (with or without overactive bladder syndrome or urodynamically confirmed detrusor overactivity) nor in patients with stress urinary incontinence (with or without detrusor overactivity) [22,32-34]. The urodynamic diagnosis or diagnoses should therefore be interpreted in combination with the individual patient's signs, symptoms and other tests to select the optimal treatment strategy. It should be kept in mind, however, that the urodynamic investigation is the most objective element of the diagnostic strategy.

It was concluded in a model study, based on a selected retrospective cohort, that urodynamic investigations are not cost effective in the primary healthcare setting for women initially presenting with predominantly stress urinary incontinence symptoms $[35,36]$. It was, however, also shown that in the referred population, urodynamic investigation is the most accurate way to obtain an objective diagnosis in patients with predominantly stress urinary incontinence symptoms [35,37]. Evidence shows that "symptomatically genuine" stress urinary incontinence does not exclude diagnosis of other abnormalities of lower urinary tract dysfunction $[30,22]$.

There is conflicting evidence that low urethral closure pressures and voiding dysfunction or an underactive detrusor are associated with poorer success rates of retropubic and transobturator midurethral, vaginal wall and transvaginal bone-anchored slings [38-42]. Leak point pressures and urethral pressures are not recommended routine tests [25]. Evidence for voiding dysfunction is regarded as useful for the individual, although in female patients both bladder outlet obstruction and underactive detrusor are not unambiguously defined 
$[25,43]$. It has also not been possible to predict very well, with contemporary urodynamic tests and analysis methods, which patients will develop voiding difficulties after surgery for stress urinary incontinence [44]. There is, however, some evidence that average and maximum flow rates may be useful in predicting post-operative voiding dysfunction and retention following retropubic and transobturator midurethral slings [45-47]. Post-hoc evidence suggests, on the other hand, that surgical procedures for stress urinary incontinence that are more "obstructive" increase the risk of de novo overactive bladder syndrome $[47,48]$.

Signs and symptoms of stress urinary incontinence can also appear after surgery for pelvic organ prolapse in women and there are several methods to uncover "occult stress urinary incontinence" in this context. However, all these methods have relatively low specificity and observer-dependent sensitivity. Concomitant procedures (with or without urodynamic investigation) to address possible de novo stress urinary incontinence after pelvic organ prolapse surgery are unreliable and the "number needed to treat" for the surgical prevention of new onset stress urinary incontinence after prolapse surgery is unfavourable $[49,50]$.

Various studies have consistently concluded that the association between symptom severity of overactive bladder syndrome and detrusor overactivity during urodynamic investigation is weak. Several studies have shown that predicting the success of pharmacological treatment for overactive bladder on the basis of the characterization of detrusor overactivity during urodynamic investigation is, as yet, impossible [51].

Comprehensive urodynamic investigation is an essential part of the evaluation of all new therapies in patients with signs and symptoms of lower urinary tract dysfunction.

\section{Male patients with symptoms of urinary incontinence}

Male patients with symptoms of lower urinary tract dysfunction based "only" on prostate enlargement, without evidence for complicating factors, and especially without incontinence, need prostate size assessment, urinary flow studies, post-void residual urine measurements, symptom scores and a frequency-volume chart prior to treatment, but do not always need to be investigated with further urodynamic investigations $[25,52]$.

Men (of any age) with urinary incontinence as the predominant symptom and/or with signs or symptoms of "other" lower urinary tract dysfunction, form a group where urodynamic investigation might be considered. In some of these men, urinary incontinence may be an initial symptom - in others it may follow treatment, be associated with neurological disease or non-urologic (e.g. pelvic or spine) disease, trauma or (surgical) treatment. Terminal dribbling is a prevalent urinary incontinence symptom in male patients and urodynamic investigation can be considered when this symptom is objectively and consistently identified in the urinary flow curve [53].

A significant number of patients suffer from urinary incontinence after radical prostatectomy (for malignancy of the prostate) and this can be related to surgical technique [54]. Recovery from urinary incontinence, in the patients that do suffer from this side-effect, occurs predominantly in the first year following surgery, with or without physiotherapy. No urodynamic investigation diagnosis is necessary in this period unless invasive therapy is considered within that year. Studies have suggested that the most common aetiology in patients with persisting urinary incontinence symptoms was urinary sphincter incompetence that causes stress urinary incontinence [55]. There is also evidence, however, that this stress urinary incontinence can occur in conjunction with detrusor overactivity, and also that detrusor overactivity with adequate sphincter function, low compliance and urethral stricture are possible causes of urinary incontinence and/or other lower urinary tract symptoms or dysfunction after radical prostatectomy $[56,57]$. There is no specific evidence for the value of frequency voiding charts and or flowmetry in this patient group. Complete urodynamic investigation including cystometry, pressure flow analysis and post void residual urine is preferable in patients with persisting incontinence or other lower urinary tract dysfunction following radical prostatectomy [57].

Retrospective studies have shown that urodynamic investigation cannot predict (stress) urinary incontinence or detrusor overactivity after surgical treatment for benign prostatic obstruction [58], although preoperative detrusor overactivity tends to persist in the postoperative period, at least temporarily [59]. Studies have shown that urodynamic investigation identifies the aetiology of lower urinary tract dysfunction in these patients; however, the value in predicting the effects of subsequent treatment is unknown [60].

Prostate size measurement, as well as the assessment of lower urinary tract symptoms, is relevant to predict urinary retention after radiotherapy for prostate cancer [61]. The evidence to support urodynamic investigation 
before radiotherapy for prostate cancer is not conclusive, but studies have shown that urodynamic investigation can identify the aetiology of lower urinary tract dysfunction after radiotherapy in this context $[62,63]$.

\section{Patients with relevant neurological abnormalities and lower urinary tract dysfunction}

New onset nocturnal enuresis or urinary incontinence in adult males is associated with many aetiologies, i.e. it can be related to ankle oedema or to prostate enlargement and ineffective voiding. It can also be an early sign of Parkinsonism [64]. Lower urinary tract dysfunction in patients with Parkinsonism can be the result of detrusor overactivity, benign prostatic obstruction (BPO), dyssynergic voiding, underactive detrusor and post-void residual urine, or any combination thereof [65]. Urodynamic investigation should be considered in all adult patients with nocturnal enuresis in whom conservative measures have failed and in whom lower urinary tract function may be considered to be affected on the basis of post-void residual urine, prostate size and or flowmetry.

Urodynamic investigation is helpul to initiate a rational treatment for the majority of patients with relevant neurological abnormalities and symptoms or "pathophysiologically suspected" lower urinary tract dysfunction $[66,67]$. Clinical outcome for patients with neurogenic dysfunction of the lower urinary tract can be improved on the basis of adequate objectivediagnosis [66-71]. Especially, urodynamic investigation can demonstrate prolonged or continuously elevated detrusor pressures during the storage phase, which is the consequence of reduced bladder compliance (or of overactive detrusor), which endangers renal function [69]. Relatively extensive evidence exists to suggest urodynamic investigation in patients with meningomyelocele and those with spinal cord lesions [66-69]. Studies to show the relevance of urodynamic investigation for neurological conditions in the elderly, are lacking, and consequently, guidelines do not provide specific recommendations for these patients [71]. Many types of lower urinary tract dysfunction are a result of, or associated with, neurological disease, and specific treatment is impossible without the knowledge that invasive urodynamic investigation provides. Flowmetry and post-void residual urine assessment are recommended in all patients with lower urinary tract dysfunction and Parkinsonism and further urodynamic investigation may be relevant for all patients that show abnormalities in these assessments [71], but evidence-based recommendations for the lower urinary tract assessment of patients with other relevant neurological abnormalities cannot be given.

\section{Frail elderly patients, with symptoms of lower urinary tract dysfunction}

Frail elderly patients are, in general, very poorly represented in all studies of urinary incontinence or lower urinary tract dysfunction, especially in those that entail invasive interventions or medications. This is because frail older patients often suffer from multiple and simultaneous impairments (e.g. poor mobility, cognitive impairment, renal failure) or conditions (heart failure, polypharmacy), which tend to exclude them from research.

Age- and gender-relevant changes in "normality" of urodynamic investigation are important in assessing the (frail) elderly $[72,73]$. Urinary incontinence in frail elderly people may be the result of a number of contributory factors, many of which are reversible by conservative and non-invasive measures. Frail elderly patients should first be evaluated by a clinician skilled in the care of older people before any invasive investigations, treatments or medications are advised to the patient. This allows easily reversible causes or contributory factors for urinary incontinence to be eliminated first, using conservative measures and therapies [74,75].

The invasive nature of urodynamic investigation becomes a more important factor in the very old or frail elderly and there is no evidence for any specific urodynamic investigation or urodynamic investigation method in this patient group.

Only a few studies have investigated whether urodynamic investigation improves clinical outcomes in the geriatric population with urinary incontinence, and there is a shortage of (positive) evidence that urodynamic investigation can predict the outcome of treatment in this context. A substantial proportion of frail older patients with overactive bladder syndrome will have urodynamic investigation confirmation of detrusor overactivity; however, this is not the case with patients with other abnormalities such as terminal detrusor overactivity with an impaired filling sensation or underactive detrusor and incomplete emptying, which are relatively prevalent [76].

Post-void residual urine is a frequent cause of urinary incontinence in frail elderly patients and "clinical observation" suggests that faecal loading can be a cause of ineffective emptying [77]. Post-void residual urine measurement by a non-invasive method, and attention to rectal filling and defecation, before any specific treatment of urinary incontinence in the frail elderly is a reasonable first step in management. Uroflowmetry (if possible) to screen for voiding abnormalities prior to 
treatment for urinary incontinence will be helpful, especially in male patients, but there is some evidence that filling cystometry as a single test has limited value in diagnosing lower urinary tract dysfunction in this patient population. Filling cystometry without pressure flow study and also one channel "simple" cystometry have unknown predictive value towards diagnosis and treatment.

If stress urinary incontinence is suspected, extra tests of urethral function and/or pelvic floor mobility may be useful. Stress urinary incontinence is not only rarer in older patients but may also be more difficult to prove, or rule out, in comparison with other cause(s) of urinary incontinence in this population [78].

Mechanisms of continence and urinary incontinence in the frail elderly, especially those related to supraspinal control or lack thereof, are increasingly better understood $[79,80]$. Establishment of the reproducibility and reliability of urodynamic investigation in the frail elderly and development of treatments for urinary incontinence in this group is desirable.

\section{Technological innovations}

There have been five technological innovations in urodynamic investigation in the last few years. Aircharged catheters may be useful for measuring the female urethra closing pressure, but there have been no clinical studies, however, to show whether they provide a reliable and acceptable alternative to the external (intrarectal and or intravesical) pressure transducer water-filled system that is considered standard technique [1]. Furthermore, data for the comparison with fluid-filled lines for measuring intravesical and intra-abdominal pressure in urodynamic investigation is lacking [81]. Comparative studies would be useful in this regard [25].

Some reports on the development of an objective method to assess bladder filling sensation during cystometry have been published [82], but it has yet to be determined that this improves the reliability, sensitivity or specificity of urodynamic investigation.

Non-invasive measurements of pressure, in combination with flow rate, in men by the penile cuff or condom catheter have been tested to diagnose bladder outlet obstruction and compared with traditional invasive measurement of pressure and flow [83-85] but not for the diagnosis or sub-classification of urinary incontinence, to date. Urethral retro-resistance pressure measurements do not give any better, or more clinically relevant, information about closure function than the urethral profiles and closure pressures or valsalva leak point pressures and are still experimental [86]. Some studies show that measurement of opening pressure from urethral pressure reflectometry can separate women with stress urinary incontinence from those with normal urinary control, but applicability, sensitivity and specificity for the clinical sub-classification of patients with symptoms of urinary incontinence are, as yet, unknown [87].

Transabdominal near-infrared spectroscopy of the detrusor muscle seems applicable in selected patients, but might be prone to artefacts and is still experimental in the clinical diagnosis of patients with urinary incontinence $[88,89]$.

\section{Conclusion}

The evidence for urodynamic testing of patients with signs and or symptoms of urinary incontinence, with or without relevant neurological abnormalities or frailty, is extensive and solid. Although pragmatic treatment of the presented symptoms is possible as a first approach, only urodynamic testing can unveil the function of the lower urinary tract, regardless of the patients' perception of (ab-)normality of signs or symptoms. Newer techniques to measure lower urinary tract function and dysfunction are in development, with the aim of reducing invasiveness whilst maintaining reliability. In the meantime, however, "traditional" urodynamic testing remains the gold standard to objectively evaluate lower urinary tract function.

\section{Disclosures}

The author declares that he has no financial disclosures.

\section{References}

I. Schäfer W, Abrams P, Liao L, Mattiasson A, Pesce F, Spangberg A, Sterling AM, Zinner NR, van Kerrebroeck P: Good urodynamic practices: uroflowmetry, filling cystometry, and pressureflow studies. Neurourol Urodyn 2002, 21 :26I-74.

2. Abrams $P$, Cardozo L, Fall M, Griffiths D, Rosier $P$, Ulmsten U, van Kerrebroeck $P$, Victor A, Wein A: The standardisation of terminology of lower urinary tract function: report from the Standardisation Sub-committee of the International Continence Society. Neurourol Urodyn 2002, 21:167-78.

3. Hashim $H$, Abrams $P$ : Is the bladder a reliable witness for predicting detrusor overactivity? J Urol 2006, I75:19|-4; discussion 194-5.

4. Schaefer W: Re: Is the bladder a reliable witness for predicting detrusor overactivity? H. Hashim and P. Abrams. J Urol 2006, I75:191-195; J Urol 2006, I76:I255-7; author reply I256-7.

5. Farag FF, Heesakkers JP: Non-invasive techniques in the diagnosis of bladder storage disorders. Neurourol Urodyn 20II, 30: | $422-8$.

6. Deirmentzoglou S, Giannitsas K, Perimenis P, Petsas T, Athanasopoulos A: Correlation of ultrasound-estimated bladder weight to urodynamic diagnoses in women with lower urinary tract symptoms. Urology 20I2, 80:66-70.

7. Winters JC, Dmochowski RR, Goldman HB, Herndon CDA, Kobashi KC, Kraus SR, Lemack GE, Nitti WW, Rovner ES, Wein AJ: Adult urodynamics: American Urological Association (AUA)/Society of Urodynamics, Female Pelvic Medicine \& Urogenital Reconstruction (SUFU) guideline. American 
Urological Association (AUA) 2012 Apr, [http://www.auanet.org/content/ media/adult_urodynamics_guideline.pdf].

8. Kortmann BB, Sonke GS, Wijkstra H, Nordling J, Kallestrup E, Holm NR, de La Rosette JJ: Intra- and inter-investigator variation in the analysis of pressure-flow studies in men with lower urinary tract symptoms. Neurourol Urodyn 2000, 19:221-32.

\section{FIOOOPrime}

9. Zimmern P, Nager CW, Albo M, Fitzgerald MP, McDermott S: Interrater reliability of filling cystometrogram interpretation in a multicenter study. J Urol 2006, 175:2174-7.

10. Ellis-Jones J, Swithinbank L, Abrams P: The impact of formal education and training on urodynamic practice in the United Kingdom: a survey. Neurourol Urodyn 2006, 25:406-10.

II. Gupta A, Defreitas G, Lemack GE: The reproducibility of urodynamic findings in healthy female volunteers: results of repeated studies in the same setting and after short-term follow-up. Neurourol Urodyn 2004, 23:3 I I-6.

12. Wyndaele JJ, de Wachter S: Cystometrical sensory data from a normal population: comparison of two groups of young healthy volunteers examined with 5 years interval. Eur Urol 2002, 42:34-8.

\section{FlOOOPrime}

13. Pauwels E, de Wachter S, Wyndaele J]: Normality of bladder filling studied in symptom-free middle-aged women. J Urol 2004, 171:1567-70.

14. Naoemova I, van Meel T, de Wachter S, Wyndaele J: Does sensory bladder function during cystometry differ from that in daily life? A study in incontinent women. Neurourol Urodyn 2009, 28:309-12.

15. Scaldazza CV, Morosetti C: Effect of different sized transurethral catheters on pressure-flow studies in women with lower urinary tract symptoms. Urol Int 2005, 75:2I-5.

\section{FlOOOPrime RECOMMENDED}

16. Harding C, Horsburgh B, Dorkin TJ, Thorpe AC: Quantifying the effect of urodynamic catheters on urine flow rate measurement. Neurourol Urodyn 2012, 3 I: 139-42.

17. Lowenstein L, Dooley Y, Kenton K, Rickey L, FitzGerald MP, Mueller E, Brubaker L: The volume at which women leak first on urodynamic testing is not associated with quality of life, measures of urethral integrity or surgical failure. J Urol 2007, 178:193-6.

18. Albo M, Wruck L, Baker J, Brubaker L, Chai T, Dandreo KJ, Diokno A, Goode P, Kraus S, Kusek JW, Lemack G, Lowder J, Steers W: The relationships among measures of incontinence severity in women undergoing surgery for stress urinary incontinence. J Urol 2007, 177:1810-4.

\section{FlOOOPrime}

\section{RECOMMENDED}

19. Nager CW, Brubaker L, Litman HJ, Zyczynski HM, Varner RE, Amundsen C, Sirls LT, Norton PA, Arisco AM, Chai TC, Zimmern P, Barber MD, Dandreo KJ, Menefee SA, Kenton K, Lowder J, Richter HE, Khandwala S, Nygaard I, Kraus SR, Johnson HW, Lemack GE, Mihova M, Albo ME, Mueller E, Sutkin G, Wilson TS, Hsu Y, Rozanski TA, Rickey LM, et al.: A randomized trial of urodynamic testing before stress-incontinence surgery. N EnglJ Med 20I2, 366: I987-97.

\section{FlOOOPrime \\ RECOMMENDED}

20. Finazzi-Agrò E, Serati M, Salvatore S, Del Popolo G: Comments on "A randomized trial of urodynamic testing before stressincontinence surgery" (N Engl J Med. 2012 May 24;366(2I): 1987-1997) From the Italian Society of Urodynamics. Neurourol Urodyn 2012.

21. Lemack GE, Zimmern PE: Identifying patients who require urodynamic testing before surgery for stress incontinence based on questionnaire information and surgical history. Urology 2000, 55:506-II.
22. Colli E, Artibani W, Goka J, Parazzini F, Wein AJ: Are urodynamic tests useful tools for the initial conservative management of non-neurogenic urinary incontinence? A review of the literature. Eur Urol 2003, 43:63-9.

23. Defreitas GA, Lemack GE, Zimmern PE, Dewey RB, Roehrborn CG, O'Suilleabhain PE: Distinguishing neurogenic from non-neurogenic detrusor overactivity: a urodynamic assessment of lower urinary tract symptoms in patients with and without Parkinson's disease. Urology 2003, 62:65I-5.

24. Miller KL, DuBeau CE, Bergmann M, Griffiths DJ, Resnick NM: Quest for a detrusor overactivity index. J Urol 2002, 167:578-84; discussion 584-5.

25. Rosier PFWM, Gajewski JB, Sand PK, Szabó L, Capewell A, Hosker GL: Executive summary: The International Consultation on Incontinence 2008-Committee on: "Dynamic Testing"; for urinary incontinence and for fecal incontinence. Part I: Innovations in urodynamic techniques and urodynamic testing for signs and symptoms of urinary incontinence in female patients. Neurourol Urodyn 2010, 29: I40-5.

26. Lucas MG, Bosch RIL, Burkhard FC, Cruz F, Madden TB, Nambiar AK Neisius A, de Ridder DJMK, Tubaro A, Turner WH, Pickard RS: EAU guidelines on surgical treatment of urinary incontinence. Eur Urol 20I2, 62:1118-29.

\section{FlOOOPrime}

27. Al-Hayek S, Belal M, Abrams P: Does the patient's position influence the detection of detrusor overactivity? Neurourol Urodyn 2008, 27:279-86.

\section{FlOOOPrime
RECOMMENDED}

28. Lose G, Griffiths D, Hosker G, Kulseng-Hanssen S, Perucchini D, Schäfer W, Thind P, Versi E: Standardisation of urethral pressure measurement: report from the Standardisation Sub-Committee of the International Continence Society. Neurourol Urodyn 2002, 21:258-60.

\section{FlOOOPrime}

\section{RECOMMENDED}

29. Sinha D, Nallaswamy V, Arunkalaivanan AS: Value of leak point pressure study in women with incontinence. J Urol 2006, 176: 186-8; discussion 188 .

30. Lemack GE: Urodynamic assessment of patients with stress incontinence: how effective are urethral pressure profilometry and abdominal leak point pressures at case selection and predicting outcome? Curr Opin Urol 2004, I4:307-II.

\section{FlOOOPrime \\ RECOMMENDED}

31. Rodríguez LV, de Almeida F, Dorey F, Raz S: Does Valsalva leak point pressure predict outcome after the distal urethral polypropylene sling? Role of urodynamics in the sling era. J Urol 2004, 172:210-4

32. van Brummen HJ, Heintz APM, van der Vaart $\mathrm{CH}$ : The association between overactive bladder symptoms and objective parameters from bladder diary and filling cystometry. Neurourol Urodyn 2004, 23:38-42.

33. Lin L, Yeh N, Lin C, Sheu B, Lin H: Comparisons of urodynamic characteristics between female patients with overactive bladder and overactive bladder plus stress urinary incontinence. Urology 2004, 64:945-9.

34. Digesu GA, Khullar V, Cardozo L, Salvatore S: Overactive bladder symptoms: do we need urodynamics? Neurourol Urodyn 2003, 22: $105-8$.

35. Martin JL, Williams KS, Abrams KR, Turner DA, Sutton AJ, Chapple C, Assassa RP, Shaw C, Cheater F: Systematic review and evaluation of methods of assessing urinary incontinence. Health Technol Assess 2006, I0: I-132, iii-iv. 
36. Weber AM, Walters MD: Cost-effectiveness of urodynamic testing before surgery for women with pelvic organ prolapse and stress urinary incontinence. Am J Obstet Gynecol 2000, 183: |338-46; discussion I346-7.

\section{FlOOOPrime \\ RECOMMENDED}

37. Agur W, Housami F, Drake M, Abrams P: Could the National Institute for Health and Clinical Excellence guidelines on urodynamics in urinary incontinence put some women at risk of a bad outcome from stress incontinence surgery? BJU Int 2009, 103:635-9.

38. Romancik M, Lutter I, Goncalves F, Pechan J, Obsitnik M, Weibl P, Havalda A: Valsalva leak point pressure predicts outcome after transobturator suburethral tape implantation-fact or fiction? Bratisl Lek Listy 2006, 107:426-9.

39. Costantini E, Lazzeri M, Giannantoni A, Bini V, Vianello A, Kocjancic E, Porena M: Preoperative Valsalva leak point pressure may not predict outcome of mid-urethral slings. Analysis from a randomized controlled trial of retropubic versus transobturator mid-urethral slings. Int Braz J Urol 2008, 34:73-8I; discussion 8I-3.

40. Sirls LT, Richter HE, Litman HJ, Kenton K, Lemack GE, Lukacz ES, Kraus SR, Goldman HB, Weidner A, Rickey L, Norton P, Zyczynski HM, KusekJW: The effect of urodynamic testing on clinical diagnosis, treatment plan and outcomes in women undergoing stress urinary incontinence surgery. J Urol 2013, 189:204-9.

\section{FloOOPrime \\ RECOMMENDED}

4l. Miller EA, Amundsen CL, Toh KL, Flynn BJ, Webster GD: Preoperative urodynamic evaluation may predict voiding dysfunction in women undergoing pubovaginal sling. I Urol 2003, 169:2234-7.

42. Lemack GE, Krauss S, Litman H, FitzGerald MP, Chai T, Nager C, Sirls L, Zyczynski H, Baker J, Lloyd K, Steers WD: Normal preoperative urodynamic testing does not predict voiding dysfunction after Burch colposuspension versus pubovaginal sling. J Urol 2008, 180:2076-80

43. Winters JC, Dmochowski RR, Goldman HB, Herndon CDA, Kobashi KC, Kraus SR, Lemack GE, Nitti VW, Rovner ES, Wein AJ: Urodynamic studies in adults: AUA/SUFU guideline. J Urol 20I2, 188:2464-72.

\section{FlOOOPrime} RECOMMENDED

44. Murray S, Lemack GE: Defining the role of urodynamics in predicting voiding dysfunction after anti-incontinence surgery: a work in progress. Curr Opin Urol 2010, 20:285-90.

45. Nager CW, FitzGerald M, Kraus SR, Chai TC, Zyczynski H, Sirls L, Lemack GE, Lloyd LK, Litman HJ, Stoddard AM, Baker J, Steers W: Urodynamic measures do not predict stress continence outcomes after surgery for stress urinary incontinence in selected women. J Urol 2008, I79:1470-4.

46. Guerette NL, Bena JF, Davila GW: Transobturator slings for stress incontinence: using urodynamic parameters to predict outcomes. Int Urogynecol J Pelvic Floor Dysfunct 2008, 19:97-102.

47. Wheeler TL, Richter HE, Greer WJ, Bowling CB, Redden DT, Varner RE: Predictors of success with postoperative voiding trials after a mid urethral sling procedure. J Urol 2008, 179:600-4.

\section{FlOOOPRime}

48. Shukla A, Paul SK, Nishtar A, Bibby J: Factors predictive of voiding problems following insertion of tension-free vaginal tape. Int $\rfloor$ Gynaecol Obstet 2007, 96:122-6.

\section{FlOOOPrime}

49. Roovers JWR, Oelke M: Clinical relevance of urodynamic investigation tests prior to surgical correction of genital prolapse: a literature review. Int Urogynecol J Pelvic Floor Dysfunct 2007, 18:455-60.
50. Roovers JPWR, van Laar JOEH, Loffeld C, Bremer GL, Mol BW, Bongers MY: Does urodynamic investigation improve outcome in patients undergoing prolapse surgery? Neurourol Urodyn 2007, 26: $170-5$.

5I. Malone-Lee J, Henshaw DJE, Cummings K: Urodynamic verification of an overactive bladder is not a prerequisite for antimuscarinic treatment response. BJU Int 2003, 92:4I5-7.

\section{FlOOOPrime \\ RECOMMENDED}

52. Rosier PF, de Wildt MJ, Wijkstra H, Debruyne FF, de La Rosette J]: Clinical diagnosis of bladder outlet obstruction in patients with benign prostatic enlargement and lower urinary tract symptoms: development and urodynamic validation of a clinical prostate score for the objective diagnosis of bladder outlet obstruction. J Urol 1996, I55:1649-54.

53. Reynard JM, Lim C, Peters TJ, Abrams P: The significance of terminal dribbling in men with lower urinary tract symptoms. Br J Urol 1996, 77:705-10.

\section{FlOOOPrime}

RECOMMENDED

54. van der Poel HG, de Blok W, Joshi N, van Muilekom E: Preservation of lateral prostatic fascia is associated with urine continence after robotic-assisted prostatectomy. Eur Urol 2009, 55:892-900.

\section{FlOOOPrime} RECOMMENDED

55. Huckabay C, Twiss C, Berger A, Nitti VW: A urodynamics protocol to optimally assess men with post-prostatectomy incontinence. Neurourol Urodyn 2005, 24:622-6.

56. McCallum TJ, Moore KN, Griffiths D: Urinary incontinence after radical prostatectomy: implications and urodynamics. Urol Nurs 2001, $21: 113-9,124$

57. Porena M, Mearini E, Mearini L, Vianello A, Giannantoni A: Voiding dysfunction after radical retropubic prostatectomy: more than external urethral sphincter deficiency. Eur Urol 2007, 52:38-45

\section{FlOOOPrime}

\section{RECOMMENDED}

58. Seki N, Takei M, Yamaguchi A, Naito S: Analysis of prognostic factors regarding the outcome after a transurethral resection for symptomatic benign prostatic enlargement. Neurourol Urodyn 2006, 25:428-32.

\section{FlOOOPrime}

\section{RECOMMENDED}

59. van Venrooij GEPM, van Melick HHE, Eckhardt MD, Boon TA: Correlations of urodynamic changes with changes in symptoms and well-being after transurethral resection of the prostate. J Urol 2002, 168:605-9.

\section{FlOOOPrime}

60. Boettcher M, Haselhuhn A, Jakse G, Brehmer B, KirschnerHermanns R: Overactive bladder syndrome: an underestimated long-term problem after treatment of patients with localized prostate cancer? BJU Int 20I2, I09:1824-30.

6I. Roeloffzen EM, van Vulpen M, Battermann JJ, van Roermund JG, Saibishkumar EP, Monninkhof EM: Pretreatment nomogram to predict the risk of acute urinary retention after I-I25 prostate brachytherapy. Int J Radiat Oncol Biol Phys 201I, 81:737-44.

62. Do V, Choo R, Deboer G, Herschorn S, Danjoux C, Chen $\mathrm{CH}$, Barak I: Urodynamic findings 3 months after radiotherapy in patients treated with conformal external beam radiotherapy for prostate carcinoma. BJU Int 2002, 90:62-7.

63. Choo R, Do V, Herschorn S, DeBoer G, Danjoux C, Morton G, Cheng $\mathrm{CH}$, Barak I, Preiner J: Urodynamic changes at 18 months post-therapy in patients treated with external beam radiotherapy for prostate carcinoma. Int J Radiat Oncol Biol Phys 2002, 53:290-6. 
64. Williams DR, Lees AJ: How do patients with parkinsonism present? A clinicopathological study. Intern Med J 2009, 39:7-I2.

65. Blackett $H$, Walker $R$, Wood $B$ : Urinary dysfunction in Parkinson's disease: a review. Parkinsonism Relat Disord 2009, I5:8I-7.

66. Wyndaele JJ: Correlation between clinical neurological data and urodynamic function in spinal cord injured patients. Spinal Cord 1997, 35:213-6.

67. Wyndaele JJ, de Sy WA: Correlation between the findings of a clinical neurological examination and the urodynamic dysfunction in children with myelodysplasia. J Urol 1985, 133 638-40.

\section{FlOOOPrime}

68. Bruschini H, Almeida FG, Srougi M: Upper and lower urinary tract evaluation of 104 patients with myelomeningocele without adequate urological management. World J Urol 2006, 24:224-8.

69. Rivas DA, Chancellor MB: Neurogenic vesical dysfunction. Urol Clin North Am 1995, 22:579-9I.

70. Moslavac S, Dzidic I, Kejla Z: Neurogenic detrusor overactivity: comparison between complete and incomplete spinal cord injury patients. Neurourol Urodyn 2008, 27:504-6.

71. Stöhrer M, Blok B, Castro-Diaz D, Chartier-Kastler E, Del Popolo G, Kramer G, Pannek J, Radziszewski P, Wyndaele J: EAU guidelines on neurogenic lower urinary tract dysfunction. Eur Urol 2009, 56:8I-8.

\section{FlOOOPrime

RECOMMENDED

72. Resnick NM, Yalla SV, Laurino E: The pathophysiology of urinary incontinence among institutionalized elderly persons. $N$ Engl J Med 1989, 320:1-7.

\section{FIOOOPrime} RECOMMENDED

73. Homma $\mathrm{Y}$, Imajo C, Takahashi S, Kawabe K, Aso Y: Urinary symptoms and urodynamics in a normal elderly population. Scand J Urol Nephrol Suppl 1994, 157:27-30.

74. Fonda D, Benvenuti F, Cottenden A, Dubeau C, Kirshner-Hermanns R, Miller K, Palmer M, Resnick N: Urinary incontinence and bladder dysfunction in older persons. In Incontinence: 2nd International Consultation on Incontinence. Edited by Abrams PCL, Khoury S, Wein A 2002. Plymouth: Plymbridge Distributing Ltd; 2002:p.625.

75. Resnick NM, Brandeis GH, Baumann MM, Morris JN: Evaluating a national assessment strategy for urinary incontinence in nursing home residents: reliability of the minimum data set and validity of the resident assessment protocol. Neurourol Urodyn 1996, 15:583-98.

76. Resnick NM, Yalla SV: Detrusor hyperactivity with impaired contractile function. An unrecognized but common cause of incontinence in elderly patients. JAMA 1987, 257:3076-8I.

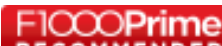

77. Dubeau CE: The aging lower urinary tract. I Urol 2006, 175: SII-5.

FlOOOPrime

78. Resnick NM, Brandeis GH, Baumann MM, DuBeau CE, Yalla SV: Misdiagnosis of urinary incontinence in nursing home women: prevalence and a proposed solution. Neurourol. Urodyn 1996, 15:599-613; discussion 613-8.

\section{FlOOOPrime}

\section{RECOMMENDED}

79. Griffiths DJ, McCracken PN, Harrison GM, Gormley EA, Moore K, Hooper R, McEwan AJ, Triscott J: Cerebral aetiology of urinary urge incontinence in elderly people. Age Ageing 1994, 23:246-50.

80. Tadic SD, Griffiths D, Schaefer W, Murrin A, Clarkson B, Resnick NM: Brain activity underlying impaired continence control in older women with overactive bladder. Neurourol Urodyn 2012, 31:652-8.

8I. Zehnder P, Roth B, Burkhard FC, Kessler TM: Air charged and microtip catheters cannot be used interchangeably for urethral pressure measurement: a prospective, single-blind, randomized trial. J Urol 2008, 180:1013-7.

82. Craggs MD: Objective measurement of bladder sensation: use of a new patient-activated device and response to neuromodulation. BJU Int 2005, 96(Suppl I):29-36.

83. Griffiths CJ, Harding C, Blake C, Mclntosh S, Drinnan MJ, Robson WA, Abrams P, Ramsden PD, Pickard RS: A nomogram to classify men with lower urinary tract symptoms using urine flow and noninvasive measurement of bladder pressure. J. Urol 2005, I74:1323-6; discussion 1326; author reply 1326.

84. Clarkson B, Robson W, Griffiths C, McArdle F, Drinnan M, Pickard R: Multisite evaluation of noninvasive bladder pressure flow recording using the penile cuff device: assessment of testretest agreement. J Urol 2008, I 80:25I5-2I.

85. Pel JJM, Bosch JLHR, Blom JHM, Lycklama à Nijeholt AAB, van Mastrigt R: Development of a non-invasive strategy to classify bladder outlet obstruction in male patients with LUTS. Neurourol Urodyn 2002, 2 I: I I7-25.

86. Slack M, Tracey M, Hunsicker K, Godwin A, Patel B, Sumeray M: Urethral retro-resistance pressure: a new clinical measure of urethral function. Neurourol Urodyn 2004, 23:656-6I.

87. Roderick T, Paul M, Christopher M, Douglas T: Urethral retroresistance pressure: association with established measures of incontinence severity and change after midurethral tape insertion. Neurourol Urodyn 2009, 28:86-9.

88. Macnab AJ, Stothers L: Development of a near-infrared spectroscopy instrument for applications in urology. Can J Urol 2008, I 5:4233-40.

FIOOOPrime
RECOMMENDED

89. Farag FF, Martens FM, Feitz WF, Heesakkers JP: Feasibility of noninvasive near-infrared spectroscopy to diagnose detrusor overactivity. Urol Int 2011, 87:330-5. 